\title{
PENGUJIAN KINERJA ROBOT KENDALI PEMADAM API BERODA DENGAN PEMANTAUAN BLUETOOTH ANDROID
}

\author{
Muhammad Haidar Ali ${ }^{1}$, Anastasya Latubessy ${ }^{2}$, Rizky Sari $\mathbf{M}^{3}$ \\ ${ }^{1,2,3)}$ Fakultas Teknik, Program Studi Teknik Informatika \\ ${ }^{1,2,3)}$ Universitas Muria Kudus \\ Email: 201651002@std.umk.ac.id ${ }^{1}, \underline{\text { anastasya.1atubessy@umk.ac.id }}^{2}, \underline{\text { rizkyumk12@ gmail.com }}^{3}$
}

(Naskah masuk: 1 Februari 2021, diterima untuk diterbitkan: 10 Maret 2021)

\begin{abstract}
ABSTRAK
Memadamkan api dilakukan secara manual oleh manusia yang mana membutuhkan banyak tenaga dalam memadamkan apinya. Oleh karena itu, dengan seiring berkembangnya kemajuan elektronika dan teknologi informatika, manusia dapat menciptakan robot pemadam api untuk membantu manusia dalam memadamkan api yang dikendalikan melalui smartphone dengan pemantauan bluetooth android. Dengan menggabungkan penggunaan smartphone android dengan arduino uno atmega328 serta bluetooth yang berfungsi sebagai penerima dan pengirim perintah dalam memadamkan api pada robot pemadam api, sehingga kegiatan memadamkan api menjadi lebih ringan dan efisien. Robot pemadam api ini juga dilengkapi dengan sensor api sebagai pendeteksi api dan arduino fan module berfungsi untuk memadamkan api. Hasil dari penelitian ini adalah terciptanya robot pemadam api beroda dengan pemantauan berbasis bluetooth dapat mendeteksi api (pada sensor api) dan kipas menyala untuk memadamkan api secara otomatis, di mana dalam menggerakkan robotnya masih secara manual sesuai perintah melalui aplikasi yaitu dengan menggunakan bantuan smartphone yang terhubung dengan bluetooth $\mathrm{HC}-05$ yang berada pada robot.
\end{abstract}

Kata Kunci: robot pemadam api, arduino uno atmega328, smartphone, bluetooth

\section{SMART ROBOT PERFORMANCE TESTING WHEEL FIRE EXTINGUISHERS WITH ANDROID BLUETOOTH MONITORING}

\begin{abstract}
Extinguishing the fire is done manually by humans which requires a lot of energy to extinguish the fire. Therefore, along with the development of advances in electronics and information technology, humans can create fire extinguishing robots to assist humans in extinguishing fires that are controlled via smartphones with android bluetooth monitoring. By combining the use of an Android smartphone with Arduino Uno Atmega328 and Bluetooth which functions as a receiver and sender of commands in extinguishing fires in fire extinguishing robots, so that fire extinguishing activities become lighter and more efficient. This fire extinguisher robot is also equipped with a fire sensor as a fire detector and an Arduino fan module to extinguish the fire. The result of this research is the creation of a wheeled fire extinguisher robot with bluetooth-based monitoring that can detect fire (on the fire sensor) and the fan turns on to extinguish the fire automatically, where the robot is still manually moving according to orders via the application, using the help of a connected smartphone. with bluetooth HC-05 which is on the robot.
\end{abstract}

Keywords: fire extinguisher robot, arduino uno atmega328, smartphone, bluetooth

\section{PENDAHULUAN}

Perkembangan teknologi elektronika maupun informatika di era globalisasi saat ini sangat pesat, membuat manusia berlomba-lomba menciptakan robot dengan berbagai bentuk dan kecanggihan dengan fungsi yang berbeda pula. Kemampuan robot dalam menyelesaikan tugasnya sangat diperhitungkan keakuratannya, sehingga dapat menunjang kinerja maksimal robot tersebut. Namun, pengontrolan robot tidaklah lepas dari sistem kendali yang dapat mengolah sinyal yang diterima ataupun yang diperintah, sehingga robot tersebut dapat melakukan tugas sesuai yang diinginkan. Seperti fungsinya, robot diciptakan untuk memudahkan manusia dalam menyelesaiakn masalah yang terjadi disekitar manusia, salah satunya dalam memadamkan api.

Memadamkan api dapat dilakukan dengan berbagai cara, yaitu dengan menggunakan air 
Jurnal Dialektika Informatika (Detika)

Vol. 1 No. 2, Mqi 2021, hlm. 27-31

maupun dengan menggunakan kipas pemadam api otomatis. Menurut Humaira Annisa \& Rahmat Rasyid (2017), robot dapat mendeteksi api dan memadamkannya dengan tegangan keluaran dari sendor api KY-026. Namun jika tegangan sensor api berada di bawah 4,1 V, maka robot akan berhenti dan mengaktifkan pompa air untuk memadamkan api pada lilin. Sedangkan menurut Salahuddin, Widdha Mellyssa, \& Azman (2018), menyatakan bahwa robot dapat mendeteksi api lilin yang berjarak $10 \mathrm{~cm}$, sehingga kipas yang digerakkan oleh motor DC akan berputas dan memadamkan api lilin hingga padam. Sistem pergerakan robot laba-laba sendiri diatur dengan menggunakan mikrokontroller Atmega32.

Pada penelitian ini, penulis membuat sebuah robot kendali beroda yang dapat memadamkan api. Penelitian ini dilakukan dengan menggabungkan penggunaan smartphone android dengan arduino uno atmega328 dan bluetooth yang berfungsi sebagai penerima dan pengirim perintah dalam memadamkan api pada robot pemadam api, sedangkan dalam memadamkan api menggunakan arduino fan module. Robot pemadam api tersebut dikendalikan melalui smartphone, sehingga kegiatan memadamkan api menjadi lebih ringan dan efisien.

\section{PENELITIAN TERKAIT}

Penelitian yang dilakukan oleh Humaira Annisa \& Rahmat Rasyid (2017) yang berjudul "Rancang Bangun Robot Cerdas Pemadam Api Beroda dengan Pemantauan Berbasis Wifi" menyatakan bahwa robot berhasil mendeteksi api dan memadamkannya dengan tegangan keluaran dari sendor api KY-026. Namun jika tegangan sensor api berada di bawah 4,1 V, maka robot akan berhenti dan mengaktifkan pompa air yang dilengkapi dengan motor servo untuk memadamkan api pada lilin. Selain itu, sensor ultrasonik tidak dapat mengukur jarak jika posisi sensor ultrasonik terhadap objek dalam kondisi serong.

Penelitian yang dilakukan oleh Sumiati, Desmira, \& Sigit Sasongko (2017) yang berjudul "Prototype Robot Pemadam Api Menggunakan Fuzzy Inference Systems Berbasis Mikrokontroler AVR Atmega328" menyatakan bahwa robot pemadam api beroda dengan menggunakan fuzzy inference systems berbasis mikrokontroler $A V R$ Atmega328 dapat mendeteksi titik api dan memadamkan api di dalam ruangan.

Penelitian yang dilakukan oleh Umam Chairul, Muhammad Kamal, \& Aidi Finawan (2017) yang berjudul "Rancang Bangun Robot Pemadam Api Menggunakan Teknik Wall Following" menyatakan bahwa sensitivitas flame detector sangat berpengaruh pada kinerja pergerakan robot pemadam api, di mana batas ideal robot di bawah api $80 \mathrm{~cm}$. Robot dapat berkomunikasi melalui bluetooth yang berupa sinyal detector, di mana
DOI: $10.24176 /$ detika.v1i2.5809 p-ISSN: 2746-2811 e-ISSN: 2774-2148

batas antara pendeteksi dengan bluetooth berjarak $20 \mathrm{~cm}$.

Penelitian yang dilakukan oleh Salahuddin, Widdha Mellyssa, \& Azman (2018) yang berjudul "Perancangan Robot Laba-Laba Pendeteksi Api Berbasis Mikrokontroller Atmega32" menyatakan bahwa robot dapat mendeteksi api lilin yang berjarak $10 \mathrm{~cm}$ sehingga kipas yang digerakkan oleh motor DC akan berputar dan memadamkan api lilin hingga padam. Titik sumber api sendiri ada pada ketinggian $\pm 20 \mathrm{~cm}$. Sistem pergerakan robot laba-laba diatur dengan menggunakan mikrokontroller Atmega32.

Penelitian yang dilakukan oleh Rumimper Reynold dkk (2016) yang berjudul "Rancang Bangun Alat Pengontrol Lampu dengan Bluetooth Berbasis Android" menyatakan bahwa alat tersebut memudahkan manusia dalam mengontrol lampu baik menghidupkan maupun mematikan lampu dengan menggunakan media handphone, di mana modul bluetooth HC-05 dapat digunakan sejauh 20 meter.

\section{METODE PENGEMBANGAN SISTEM}

Awal mula dalam sistem perancangan, program dibuat melalui aplikasi arduino IDE dengan menggunakan Bahasa Pemrograman. Program yang sudah jadi selanjutkan diupload ke dalam arduino uno atmega328. Jika program sukses diupload, arduino memproses script program yang dibuat untuk mengaktifkan sensor api (flame sensor) yang terpasang pada arduino tersebut.

Sensor api yang sudah aktif mulai mendeteksi kondisi sekitar guna mendeteksi adanya nyala panas api. Setelah proses mendeteksi api selesai, sistem pada arduino akan menghasilkan output yang menyalakan sensor kipas (fan module) untuk memadamkan api. Sedangkan untuk menggerakkan robot pemadam api, digerakkan secara manual menggunakan aplikasi yang terdapat pada smartphone yang sudah terhubung dengan bluetooth.

Gambar 8 menunjukkan rancangan blok diagram robot kendali pemadam api beroda dengan pemantauan bluetooth android.

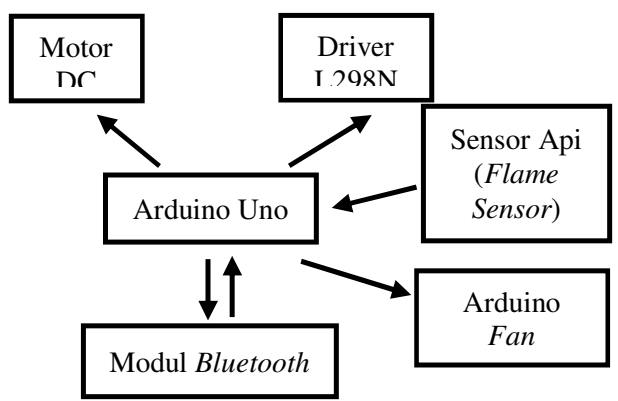

Gambar 8 Rancang Diagram Blok Robot Kendali Pemadam Api Beroda dengan Pemantauan Bluetooth Android 
Jurnal Dialektika Informatika (Detika)

Vol. 1 No. 2, Mqi 2021, hlm. 27-31
DOI: $10.24176 /$ detika.vli2.5809

p-ISSN: 2746-2811

e-ISSN: 2774-2148

\begin{tabular}{ccc}
\hline Modul L298N & Ya & Normal \\
\hline Roda / Motor DC & Ya & Normal \\
\hline
\end{tabular}

Tabel 7. Kinerja Bluetooth Hari Ketiga

\begin{tabular}{cc}
\multicolumn{2}{c}{ Bluetooth } \\
\hline Jarak & Hasil Kinerja \\
\hline $0-3$ meter & Berjalan Normal \\
\hline $3-5$ meter & Berjalan Normal \\
\hline $5-7$ meter & Berjalan Normal \\
\hline
\end{tabular}

Tabel 8. Kinerja Sensor Api Hari Ketiga

\begin{tabular}{cc}
\hline \multicolumn{2}{c}{ Sensor Api } \\
\hline Jarak & Hasil Kinerja \\
\hline $0-3 \mathrm{~cm}$ & Berjalan Normal \\
\hline $3-5 \mathrm{~cm}$ & Berjalan Normal \\
\hline $5-7 \mathrm{~cm}$ & Berjalan Normal \\
\hline $7-10 \mathrm{~cm}$ & Berjalan Normal \\
\hline
\end{tabular}

Tabel 9. Kondisi Komponen Hari Ketiga

\begin{tabular}{ccc}
\hline \multirow{2}{*}{ Komponen } & \multicolumn{2}{c}{ Kondisi } \\
\cline { 2 - 3 } & Berfungsi & Suhu \\
\hline Arduino UNO & Ya & Normal \\
\hline Bluetooth & Ya & Normal \\
\hline Sensor Api & Ya & Normal \\
\hline Sensor Kipas L9110 & Ya & Normal \\
\hline Modul L298N & Ya & Normal \\
\hline Roda / Motor DC & Ya & Normal \\
\hline
\end{tabular}

Berikut ini hasil pengujian kinerja sistem robot menggunakan metode Black Box, ditunjukkan pada Tabel 10.

Tabel 3. Kondisi Komponen Hari Pertama

\begin{tabular}{ccc}
\hline \multirow{2}{*}{ Komponen } & \multicolumn{2}{c}{ Kondisi } \\
\cline { 2 - 3 } & Berfungsi & Suhu \\
\hline Arduino UNO & Ya & Normal \\
\hline Bluetooth & Ya & Normal \\
\hline Sensor Api & Ya & Normal \\
\hline Sensor Kipas L9110 & Ya & Normal \\
\hline Modul L298N & Ya & Normal \\
\hline Roda / Motor DC & Ya & Normal \\
\hline
\end{tabular}

Tabel 4. Kinerja Bluetooth Hari Kedua

\begin{tabular}{cc}
\hline \multicolumn{2}{c}{ Bluetooth } \\
\hline Jarak & Hasil Kinerja \\
\hline $0-3$ meter & Berjalan Normal \\
\hline $3-5$ meter & Berjalan Normal \\
\hline $5-7$ meter & Berjalan Normal \\
\hline
\end{tabular}

Tabel 5. Kinerja Sensor Api Hari Kedua

\begin{tabular}{cc}
\hline \multicolumn{2}{c}{ Sensor Api } \\
\hline Jarak & Hasil Kinerja \\
\hline $0-3 \mathrm{~cm}$ & Berjalan Normal \\
\hline $3-5 \mathrm{~cm}$ & Berjalan Normal \\
\hline $5-7 \mathrm{~cm}$ & Berjalan Normal \\
\hline $7-10 \mathrm{~cm}$ & Berjalan Normal \\
\hline
\end{tabular}

Tabel 6. Kondisi Komponen Hari Kedua

\begin{tabular}{ccc}
\hline \multirow{2}{*}{ Komponen } & \multicolumn{2}{c}{ Kondisi } \\
\cline { 2 - 3 } & Berfungsi & Suhu \\
\hline Arduino UNO & Ya & Normal \\
\hline Bluetooth & Ya & Normal \\
\hline Sensor Api & Ya & Normal \\
\hline Sensor Kipas L9110 & Ya & Normal \\
\hline
\end{tabular}

Tabel 10. Black Box Sistem

\begin{tabular}{|c|c|c|c|c|c|}
\hline No & $\begin{array}{c}\text { Skenario } \\
\text { pengujian }\end{array}$ & $\begin{array}{l}\text { Test } \\
\text { Case }\end{array}$ & $\begin{array}{c}\text { Hasil } \\
\text { yang } \\
\text { diharapk } \\
\text { an }\end{array}$ & $\begin{array}{c}\text { Hasil } \\
\text { pengujia } \\
\mathbf{n}\end{array}$ & $\begin{array}{c}\text { Kesim } \\
\text { pulan }\end{array}$ \\
\hline 1. & $\begin{array}{l}\text { Menyalaka } \\
\mathrm{n} \text { api di } \\
\text { area sensor } \\
\text { api }\end{array}$ & $\begin{array}{l}\text { Penguji } \\
\text { an } \\
\text { sensor } \\
\text { api }\end{array}$ & $\begin{array}{l}\text { Sistem } \\
\text { akan } \\
\text { menangk } \\
\text { ap panas } \\
\text { api } \\
\text { kemudian } \\
\text { menyalak } \\
\text { an kipas }\end{array}$ & Sesuai & Valid \\
\hline 2. & $\begin{array}{l}\text { Menghubun } \\
\text { gkan } \\
\text { Bluetooth } \\
\text { pada HP ke } \\
\text { Bluetooth } \\
\text { HC-05 }\end{array}$ & $\begin{array}{l}\text { Penguji } \\
\text { an } \\
\text { Blueto } \\
\text { oth }\end{array}$ & $\begin{array}{l}\text { Sistem } \\
\text { akan } \\
\text { terhubun } \\
\text { g dengan } \\
\text { HP dan } \\
\text { akan } \\
\text { menggera } \\
\text { kan robot } \\
\text { sesuai } \\
\text { perintah } \\
\text { melalui } \\
\text { aplikasi }\end{array}$ & Sesuai & Valid \\
\hline
\end{tabular}

Berikut ini hasil pengujian kinerja sistem robot menggunakan metode White Box, ditunjukkan pada Tabel 11.

Tabel 11. White Box Sistem

\begin{tabular}{lll}
\hline No & Baris Program & \\
\hline (1) & \#define ENA 7 & // pin 7 \\
& \#define ENB 6 & // pin 6 \\
\hline
\end{tabular}


Jurnal Dialektika Informatika (Detika)

\#define IN_1 5 // driver in to pin 5

\#define IN_2 4 // driver in to pin 4

\#define IN_3 3 // driver in to pin 3

\#define IN_4 2 // driver in to pin 2

int command; // status perintah

int speedCar $=150 ; \quad / / 0-255$.

int speed_Coeff $=4$;

int pinSensor $=8$;

int pinKipas $=9$

(2) void $\operatorname{setup}()$

pinMode(ENA, OUTPUT);

pinMode(ENB, OUTPUT);

pinMode(IN_1, OUTPUT);

pinMode(IN_2, OUTPUT);

pinMode(IN 3, OUTPUT);

pinMode(IN_4, OUTPUT);

pinMode(pinSensor, INPUT);

pinMode(pinKipas, OUTPUT);

Serial.begin $(9600)$

(3)

void goAhead()\{

digitalWrite(IN 1, HIGH);

digitalWrite(IN_2, LOW);

analogWrite(ENA, speedCar);

digitalWrite(IN_3, LOW);

digitalWrite(IN_4, HIGH);

(4) void goBack()\{

digitalWrite(IN_1, LOW); digitalWrite(IN_2, HIGH); analogWrite(ENA, speedCar); digitalWrite(IN_3, HIGH); digitalWrite(IN_4, LOW);

analogWrite(ENB, speedCar);

(5) void goRight ()\{

digitalWrite(IN 1, LOW);

digitalWrite(IN_2, HIGH);

analogWrite(ENA, speedCar); digitalWrite(IN 3, LOW); digitalWrite(IN_4, HIGH); analogWrite(ENB, speedCar);

(6)

id goLeft()\{

digitalWrite(IN_1, HIGH);

digitalWrite(IN_2, LOW);

analogWrite(ENA, speedCar);

digitalWrite(IN_3, HIGH);

digitalWrite(IN_4, LOW);

analogWrite(ENB, speedCar);

(7) void stopRobot()

digitalWrite(IN_1, LOW); digitalWrite(IN_2, LOW); analogWrite(ENA, speedCar); digitalWrite(IN_3, LOW); digitalWrite(IN_4, LOW);

analogWrite(ENB, speedCar);

(8) void api ()\{

int nilai $=$ digitalRead(pinSensor $)$;

Serial.println(nilai);

(9) if (nilai == HIGH) \{

digitalWrite(pinKipas, HIGH);

(10) Serial.println("Api terdeteksi");

(11) \} else \{

(12) digitalWrite(pinKipas, LOW);
e-ISSN: 2774-2148
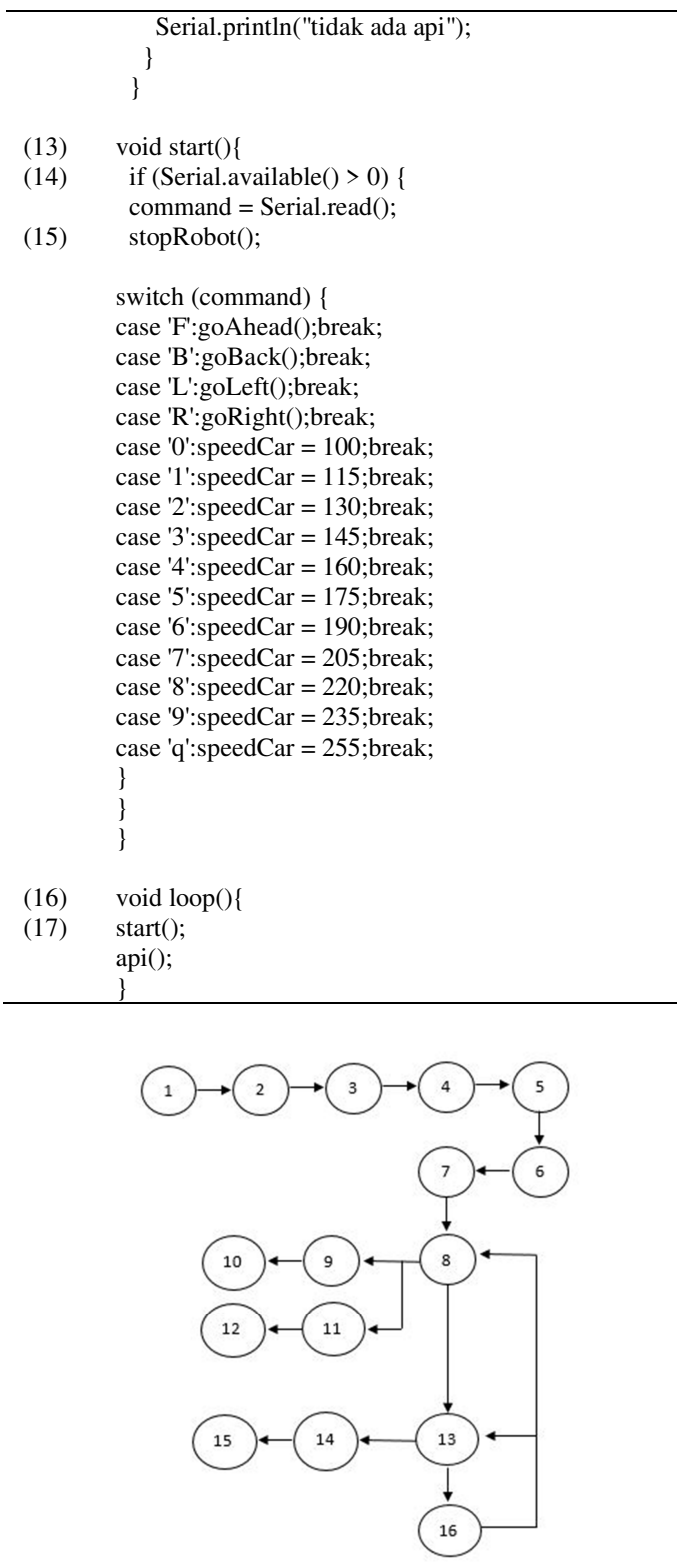

Gambar 10. Cyclomatic Graph Sistem

Perhitungan cc dari cyclomatic graph pada gambar 1 sebagai berikut:

$\mathrm{V}(\mathrm{G})=\mathrm{E}-\mathrm{N}+2$

$\mathrm{V}(\mathrm{G})=(17-16)+2$

$\mathrm{V}(\mathrm{G})=1+2$

$\mathrm{V}(\mathrm{G})=3$

Di mana E merupakan jumlah busur/link, dan $\mathrm{N}$ merupakan jumlah node/simpul.

\section{KESIMPULAN DAN SARAN}

Berdasarkan hasil penelitian yang telah dilakukan, diperoleh kesimpulan bahwa, dengan adanya robot pemadam api beroda berbasis arduino uno dengan menggunakan bluetooth dapat meringankan pekerjaan manusia dalam membantu 
Jurnal Dialektika Informatika (Detika)

Vol. 1 No. 2, Mqi 2021, hlm. 27-31

memadamkan api. Disamping itu, hasil pengujian sensor api, sistem menangkap panas api di area sensor api sehingga dapat menyalakan kipas untuk memadamkan api. Hasil pengujian bluetooth dengan menghubungkan bluetooth pada smartphone ke bluetooth, sistem terhubung dengan smartphone sehingga dapat menggerakkan robot sesuai perintah melalui aplikasi.

Sedangkan saran yang dapat peneliti sampaikan adalah, Robot pemadam api beroda berbasis arduino menggunakan bluetooth masih bisa dikembangkan lebih luas lagi. Untuk peneliti selanjutnya, diharapkan dapat meningkatkan kualitas sensor maupun pergerakan robot agar dapat menunjang sistem robot lebih baik lagi.

\section{DAFTAR PUSTAKA}

Humaira, Annisa \& Rahmat Rasyid. 2017. Rancang Bangun Robot Cerdas Pemadam Api Beroda dengan Pemantauan Berbasis Wifi. Jurnal Fisika Unand, 6 (4): 368 - 374. ISSN: 2302 -8491 .
DOI: $10.24176 /$ detika.v1i2.5809 p-ISSN: 2746-2811 e-ISSN: 2774-2148

Rumimper, Reynold, Sherwin R.U.A. Sompie, \& Dringhuzen J. Mamahit. 2016. Rancang Bangun Alat Pengontrol Lampu dengan Bluetooth Berbasis Android. E-Journal Teknik Elektro dan Komputer, 5 (3): 24 - 33. ISSN: $2301-8402$.

Salahuddin, Widdha Mellyssa, \& Azman. 2018. Perancangan Robot Laba-Laba Pendeteksi Api Berbasis Mikrokontroller Atmega32. Journal of Islamic Science and Technology, 4 (1): 79 - 88. Diakses dari www.jurnal.arraniry.com/index.php/elkawnie .

Sumiati, Desmira, \& Sigit Sasongko. 2017. Prototype Robot Pemadam Api Menggunakan Fuzzy Inference Systems Berbasis Mikrokontroler AVR Atmega328. Jurnal Penelitian dan Pengabdian Masyarakat, 5 (2): 186 - 198.

Umam Chairul, Muhammad Kamal, \& Aidi Finawan. 2017. Rancang Bangun Robot Pemadam Api Menggunakan Teknik Wall Following. Jurnal Tektro, 1 (1): 29 - 34. ISSN: $2581-2890$. 